Arq. Bras. Med. Vet. Zootec., v.66, n.2, p.583-592, 2014

\title{
Qualidade da carne de suínos com uso de glicerina na alimentação
}

\author{
[Meat quality of swine with the use of glycerin in feeding] \\ D.S. Melo, P.B. Faria*, V.S. Cantarelli, M.F.M. Rocha, A.M.B.G. Pinto, E.M. Ramos \\ Universidade Federal de Lavras - Lavras, MG
}

\begin{abstract}
RESUMO
O objetivo deste trabalho foi avaliar os efeitos do fornecimento de diferentes níveis de glicerina na alimentação sobre a qualidade da carne de suínos em terminação. Foram utilizados 30 machos castrados e 30 fêmeas que apresentaram peso inicial de 79,3 $\pm 4,0 \mathrm{~kg}$. Utilizou-se delineamento em blocos casualizados (peso inicial) em esquema fatorial $2 \times 4+2$, sendo duas categorias sexuais (macho castrado e fêmea), quatro níveis de glicerina bruta $(50,100,150$ e $200 \mathrm{~g} / \mathrm{kg}$ ) e dois grupos controle (macho castrado e fêmea alimentados com dieta sem glicerina), totalizando dez tratamentos com seis repetições e a unidade experimental representada por um animal. Após o abate, foram realizadas as análises físico-químicas e centesimais dos músculos Longissimus dorsi (lombo) e Semimembranosus (pernil) do lado esquerdo das carcaças. Os resultados mostraram interação entre os níveis de glicerina e sexo para a intensidade de vermelho e cinzas no pernil. Observou-se que, nos corte do lombo, o $\mathrm{pH}$ final dos machos castrados foi maior do que o das fêmeas suínas. Os resultados indicaram que suínos machos castrados apresentaram maior teor de extrato etéreo no pernil e no lombo quando comparados às fêmeas. No pernil, o teor de cinzas das fêmeas suínas foi superior ao dos machos castrados. Entretanto, no lombo, não se verificou influência dos níveis de glicerina sobre a composição centesimal. Contudo, apesar de o uso da glicerina ter ocasionado modificação na cor vermelha e teor de cinzas no pernil de machos castrados, de forma geral não provocou mudanças relevantes sobre as características físico-químicas e centesimais da carne de suínos, podendo ser utilizada até o nível de $200 \mathrm{~g} / \mathrm{kg}$ na alimentação desses animais.
\end{abstract}

Palavras-chaves: biocombustível, composição centesimal, composição físico-química

\begin{abstract}
The objective of this study was to evaluate the effects of providing different levels of glycerin in the diet on meat quality of finishing pigs. 30 barrow and 30 female pigs were used, with initial weight of $79.3 \pm 4.0 \mathrm{~kg}$. A randomized block design was used (initial weight) in a factorial $2 \times 4+2$, being two sex categories (barrow and female), four levels of crude glycerin (50,100,150 and 200 $/ \mathrm{kg}$ ) and two control groups (barrow and female fed diet without glycerin), in a total of ten treatments with six replications and the experimental unit represented by an animal. After slaughter were carried out the physico-chemical and centesimal analysis of Longissimus dorsi (loin) and Semimembranosus (ham) on the left side of the carcasses. The results showed interaction between barrows and levels of glycerin to the redness and ash of the ham. It was observed that in the loin cut the final pH of the barrows was higher than the female pigs. The results indicate that barrows had higher ether extract content in the ham and loin compared to females. In the shank, the ash content of sows was higher than that of barrows. However, in the loin, there was no influence of the levels of glycerin on chemical composition. Nevertheless, despite the use of glycerin having caused changes in the red color and ash content in the leg of castrated males, in general it did not cause significant changes on the physico-chemical and centesimal characteristics of pork and can be used up to the level of $200 \mathrm{~g} / \mathrm{kg}$ in the feed of these animals.
\end{abstract}

Keywords: biofuel, centesimal composition. physical-chemical composition

Recebido em 20 de setembro de 2012

Aceito em 1 de outubro de 2013

*Autor para correspondência (corresponding author)

E-mail: peterbfvet@yahoo.com.br

Financiado pela FAPEMIG (Fundação de Amparo à Pesquisa do Estado de Minas Gerais) 


\section{INTRODUÇÃO}

A busca por combustíveis alternativos ao petróleo transformou-se em objetivo comum de centros de pesquisa em todo o mundo nos últimos anos. Dessa forma, vem aumentando a cada dia usinas produtoras de combustíveis que não utilizam fontes fósseis como matéria-prima. Em destaque está a produção do biodiesel. No entanto, o crescimento da produção de biocombustíveis tem gerado um excedente de glicerina, de modo que o mercado tem encontrado dificuldade para absorção desse subproduto.

A disponibilidade de glicerina aumentou (Agência..., 2012), trazendo redução do preço, e outras formas de utilização foram criadas com intuito de melhorar o aproveitamento. Sendo assim, o uso de glicerina ou glicerol na alimentação animal pode ser uma alternativa interessante, não só na redução do custo das dietas, mas também para contribuir com a sustentabilidade da produção de biodiesel. O principal uso da glicerina na alimentação animal seria como fonte energética para inclusão diretamente na alimentação animal.

Para a produção de suínos, a alimentação é um dos fatores de maior custo no sistema produtivo, devido à grande utilização de soja e milho na composição das rações. Além disso, a qualidade da carne pode sofrer influências significativas de acordo com o tipo e quantidade de alimento fornecido. E, apesar da grande perspectiva de uso da glicerina na produção de suínos, estudos relacionados a alterações em relação aos aspectos físico-químicos da carne ainda são escassos. Mourot et al. (1994), utilizando 5\% de glicerina em dietas para suínos em terminação, verificaram uma maior capacidade de retenção de água no músculo Longissimus dorsi, proporcionando uma carne de qualidade superior. Berenchtein et al. (2010), trabalhando com glicerina para suínos em terminação até o nível de $9 \%$, não verificaram efeito sobre os valores de $\mathrm{pH}$, perda de peso por gotejamento e luminosidade. Enquanto Gomide et al. (2012) verificaram redução da perda de peso por descongelamento e da força de cisalhamento com aumento dos níveis de glicerina de até $16 \%$, indicando melhora nos aspectos da qualidade da carne de suínos.
Dessa forma, mais estudos devem ser realizados com a glicerina bruta, uma vez que o glicerol é utilizado na lipogênese e mesmo na gliconeogênese (Lin, 1977), o que poderia contribuir para aumento nos teores de lipídeos na carne, redução da catálise de aminoácidos e maior acúmulo de proteína no músculo, além da possibilidade de alteração dos parâmetros de qualidade da carne, dependendo do nível de inclusão na dieta, principalmente de suínos em terminação.

O objetivo deste estudo foi avaliar os efeitos do fornecimento de diferentes níveis de glicerina na alimentação sobre a qualidade da carne de suínos em terminação.

\section{MATERIAL E MÉTODOS}

Os animais foram criados no Galpão de Terminação do Setor de Suinocultura do Departamento de Zootecnia da Universidade Federal de Lavras (UFLA), no município de Lavras, MG. Foram utilizados 30 suínos machos castrados e 30 fêmeas da genética Topigs, com peso médio inicial de $79,3 \pm 4,0 \mathrm{~kg}$ e terminados com peso de $106,2 \pm 4,5 \mathrm{~kg}$. Este estudo foi aprovado pelo Comitê de Ética no Uso de Animais da UFLA, com o número de protocolo 011/2010. Distribuíram-se os animais em 30 baias de piso concreto $(2,3 \times 1,5 \mathrm{~m})$, dotadas de comedouros semiautomáticos e bebedouros tipo chupeta, no galpão de terminação. Em cada baia foram alojados dois animais (um macho castrado e uma fêmea). A temperatura mínima no galpão foi de $19,5 \pm 3,4^{\circ} \mathrm{C}$ e a máxima, de $26,2 \pm 2,8^{\circ} \mathrm{C}$.

Os animais foram distribuídos em delineamento em blocos casualizados, com esquema fatorial 2 x $4+2$, sendo um macho castrado e uma fêmea, quatro níveis de glicerina bruta na dieta $(50,100$, 150 e $200 \mathrm{~g} / \mathrm{kg}$ ) e dois tratamentos com dieta sem glicerina; totalizando 10 tratamentos, seis repetições e a unidade experimental representada por um animal.

As rações experimentais foram formuladas à base de milho e farelo de soja, suplementadas com vitaminas, minerais e aminoácidos, para atenderem às exigências mínimas sugeridas por Rostagno et al. (2005) para machos castrados de alto potencial genético, dos 70 aos $100 \mathrm{~kg}$ (Tab. 1), com utilização de diferentes níveis de glicerina bruta (Tab. 2). 
Os tratamentos foram realizados da seguinte forma: Tratamento 1 - ração basal sem adição de glicerina; Tratamento $2-50 \mathrm{~g} / \mathrm{kg}$ de glicerina em substituição ao milho da ração basal na matéria natural; Tratamento $3-100 \mathrm{~g} / \mathrm{kg}$ de glicerina em substituição ao milho da ração basal na matéria natural; Tratamento $4-150 \mathrm{~g} / \mathrm{kg}$ de glicerina em substituição ao milho da ração basal na matéria natural; e Tratamento 5 - 200g/kg de glicerina em substituição ao milho da ração basal na matéria natural. Os animais receberam água e ração à vontade durante o período experimental de 30 dias.

Tabela 1. Composição centesimal e valores calculados das dietas experimentais

\begin{tabular}{|c|c|c|c|c|c|}
\hline \multirow{2}{*}{ Ingredientes } & \multicolumn{5}{|c|}{ Níveis de glicerina ( $\mathrm{g} / \mathrm{kg}$ de matéria natural) } \\
\hline & 0 & 50 & 100 & 150 & 200 \\
\hline Milho triturado & 707 & 654,5 & 603,0 & 551,0 & 499,0 \\
\hline Farelo de soja & 229 & 238 & 247 & 258 & 266 \\
\hline Glicerina bruta & 0 & 50 & 100 & 150 & 200 \\
\hline Óleo de Soja & 20,0 & 16,8 & 13,3 & 9,0 & 5,9 \\
\hline Fosfato bicálcico & 11,2 & 11,2 & 11,2 & 11,2 & 11,2 \\
\hline Calcário calcítico & 7,7 & 7,7 & 7,7 & 7,7 & 7,7 \\
\hline Sal $(\mathrm{NaCl})$ & 3,6 & 1,35 & 0 & 0 & 0 \\
\hline Premix Mineral $^{1}$ & 1,0 & 1,0 & 1,0 & 1,0 & 1,0 \\
\hline Premix Vitamínico ${ }^{2}$ & 1,0 & 1,0 & 1,0 & 1,0 & 1,0 \\
\hline DL-Metionina 99 & 0,09 & 0,1 & 0,1 & 0,1 & 0,15 \\
\hline L-Lisina 99 & 1,5 & 1,35 & 1,2 & 1,0 & 0,9 \\
\hline L-Treonina 98 & 0,07 & 0,07 & 0,07 & 0,07 & 0,07 \\
\hline Tylan $^{3}$ & 0,2 & 0,2 & 0,2 & 0,2 & 0,2 \\
\hline Caulim & 17,64 & 16,73 & 14,23 & 9,73 & 6,88 \\
\hline \multicolumn{6}{|l|}{ Valores calculados } \\
\hline Metabolizável & 3.250 & 3.250 & 3.250 & 3.250 & 3.250 \\
\hline Lisina digestível(g/kg) & 8,19 & 8,21 & 8,23 & 8,27 & 8,31 \\
\hline Metionina digestível $(\mathrm{g} / \mathrm{kg})$ & 2,50 & 2,50 & 2,50 & 2,50 & 2,50 \\
\hline Proteína bruta (g/kg) & 160,2 & 160,2 & 160,2 & 160,2 & 160,2 \\
\hline Treonina digestível (g/kg) & 5,50 & 5,50 & 5,50 & 5,50 & 5,50 \\
\hline Fósforo disponível (g/kg) & 3,00 & 3,00 & 3,00 & 3,00 & 3,00 \\
\hline Cálcio (g/kg) & 6,50 & 6,50 & 6,50 & 6,50 & 6,50 \\
\hline
\end{tabular}

${ }^{1}$ Composição por kg do produto: cálcio, 98.800mg; cobalto, $185 \mathrm{mg}$; cobre, $15,750 \mathrm{mg}$; ferro, 26.250mg; iodo, $1.470 \mathrm{mg}$; manganês, $41.850 \mathrm{mg}$; zinco, $77.999 \mathrm{mg}$. ${ }^{2}$ Composição por kg do produto: ácido fólico, $116,55 \mathrm{mg}$; ácido pantotênico, 2.333,5mg; biotina, 5,28mg; niacina, 5.600mg; piridoxina, 175mg; riboflavina, 933,3mg; tiamina, 175mg; Vit. A, 1.225.000U.I.; Vit. $\mathrm{D}_{3}$, 315.000U.I.; Vit. E, 1.400mg; Vit. $\mathrm{K}_{3}$, 700mg; Vit. B12, 6.825mg; selênio, $105 \mathrm{mg}$; antioxidante: $1.500 \mathrm{mg}$. ${ }^{3}$ Antibiótico à base de tilosina granulada.

Tabela 2. Composição e características da glicerina utilizada

\begin{tabular}{lc}
\hline Características & Resultados \\
\hline Cloreto de sódio, g/kg & 36,8 \\
Sódio, g/kg & 25,1 \\
Metanol, g/ $/ \mathrm{kg}^{2}$ & 0,2 \\
Resíduos Orgânicos, g/ $\mathrm{kg}^{2}$ & $<0,1$ \\
Umidade, g/ $\mathrm{kg}^{2}$ & 111,2 \\
Cinzas, g/ $\mathrm{kg}^{2}$ & 60,6 \\
Densidade, $\mathrm{g} / \mathrm{ml}^{2}$ & 1,264 \\
Glicerol, g/ $\mathrm{kg}^{2}$ & 831,2 \\
Cor 2,3 & AMAR \\
\hline 1 - Laudo fornecido pelo laboratório CBO - Análises Laboratoriais; 2 - Laudo fornecido pela Petrobrás; 3- \\
Glicerina cor amarelo-claro.
\end{tabular}


Ao final do experimento, após jejum e dieta hídrica por 12 horas, os animais foram abatidos sob condições humanitárias, através de insensibilização elétrica (eletronarcose), com realização posterior da sangria e evisceração.

Após 24 horas de resfriamento das carcaças em câmara fria $\left( \pm 5^{\circ} \mathrm{C}\right)$, foi realizada a coleta de amostras dos músculos Longissimus dorsi (lombo) e Semimembranosus (pernil) do lado esquerdo das carcaças. As amostras foram transportadas refrigeradas para o Laboratório e em seguida congeladas para posterior determinação das características físico-químicas dos cortes.

As análises físico-químicas foram realizadas no Laboratório de Tecnologia de Carnes e Pescado do Departamento de Ciência dos Alimentos da UFLA. Realizaram-se as determinações de $\mathrm{pH}$ com potenciômetro DIGIMED DM-20 acoplado a um eletrodo. $\mathrm{O}$ valores de $\mathrm{pH}$ inicial $(\mathrm{pHi})$ foram tomados no músculo Longissimus dorsi aos 45 minutos após o abate, e os valores de $\mathrm{pH}$ final (pHf) foram tomados nos músculos Longissimus dorsi e Semimembranosus 24 horas após resfriamento. Para cor, utilizou-se colorímetro MINOLTA CR 200b (Osaka, Japão), operando no sistema CIEL*a*b*, com iluminante D65. Para a cor ainda foram determinados os índices de saturação $\left(C^{*}\right)$ e o ângulo de tonalidade $\left(\mathrm{h}^{*}\right)$, que foram calculados pelas seguintes fórmulas (Ramos e Gomide, 2007): $C^{*}=\left(a^{*} 2+b^{*} 2\right) 1 / 2 \mathrm{e} ; h^{*}=\tan -1\left(b^{*} / a^{*}\right)$.

A análise de perda de água por descongelamento foi realizada segundo metodologia preconizada por Farouk e Price (1994). Para determinação da perda de peso por cocção (PPC), as amostras foram pesadas em balança semianalítica METTLER M P1210 (Toledo, Brasil), envolvidas em papel alumínio e submetidas a cozimento em chapa elétrica a $150^{\circ} \mathrm{C}$ até ultrapassar $\quad 72^{\circ} \mathrm{C}$ (Amasa, 1978). Para determinação da maciez, utilizou-se metodologia de Froning e Uijttenboogarte (1988), em que as amostras foram obtidas com amostrador cilíndrico de $1,27 \mathrm{~cm}$ de diâmetro e posteriormente seccionadas no sentido transversal das fibras musculares, usando uma sonda Warner Bratzler acoplada a um texturômetro modelo TA XT-2.
As amostras para composição centesimal foram preparadas com a retirada da pele, tecido adiposo e aponeuroses, seguida de homogeneização. As análises de umidade, proteína, extrato etéreo e cinzas foram realizadas conforme Horwitz (2000), em duplicata.

Analisaram-se os dados pelo programa estatístico $\mathrm{SAS}^{\circledR}$. As variáveis com respostas de efeitos significativos na análise de variância (Teste F) para os fatores níveis de glicerina e sexo e/ou interação entre essas variáveis foram submetidas à regressão com 5\% de probabilidade.

\section{RESULTADOS E DISCUSSÃO}

Os resultados não mostraram influência do uso da glicerina bruta sobre as características físico-químicas do lombo e do pernil, independentemente do nível de utilização na alimentação dos suínos (Tab. 3). Entretanto, os resultados evidenciam que suínos machos castrados apresentaram maior valor de $\mathrm{pH}$ final no lombo $(\mathrm{P}<0,05)$ quando comparados às fêmeas em terminação (Tab. 3).

$\mathrm{Na}$ literatura, alguns poucos trabalhos que foram desenvolvidos com o objetivo de determinar os efeitos da glicerina, oriunda de diferentes fontes, sobre características de qualidade de carne suína não relataram alterações dos parâmetros avaliados. Mendoza et al. (2010), trabalhando com nível de inclusão de até $150 \mathrm{~g} / \mathrm{kg}$ de glicerina, reportaram um comportamento semelhante ao encontrado neste trabalho, apresentando resultados médios próximos aos deste estudo para o lombo.

Resultados semelhantes aos deste estudo também foram encontrados por Berenchtein et al. (2010) que, trabalhando com glicerina semipurificada (80g/100g de glicerol) como ingrediente energético das rações de suínos em crescimento e terminação até o nível de $90 \mathrm{~g} / \mathrm{kg}$, não verificaram efeito $(\mathrm{P}<0,05)$ sobre os valores de $\mathrm{pH}$, perda de peso por gotejamento e luminosidade. Lammers et al. (2008), avaliando níveis de 0,50 e $100 \mathrm{~g} / \mathrm{kg}$ de inclusão de glicerina na dieta, também não relataram influência da dieta sobre os parâmetros de qualidade de carne. 
Tabela 1. Médias dos componentes físico-químicos dos cortes do lombo de suínos em função do nível de glicerina da alimentação e do sexo

\begin{tabular}{|c|c|c|c|c|c|c|c|c|c|c|c|c|}
\hline \multirow[t]{2}{*}{ Cortes } & & \multicolumn{5}{|c|}{$\begin{array}{c}\text { Níveis de glicerina ( } \mathrm{g} / \mathrm{kg} \text { de matéria } \\
\text { natural) }\end{array}$} & \multicolumn{2}{|c|}{ Sexo } & \multirow{2}{*}{$\begin{array}{l}\mathrm{CV} \\
(\%)\end{array}$} & \multicolumn{3}{|c|}{ Valor de $\mathrm{P}^{1}$} \\
\hline & & 0 & 50 & 100 & 150 & 200 & Macho & Fêmea & & $\mathrm{N}$ & S & $\mathrm{N} \times \mathrm{S}$ \\
\hline \multirow{10}{*}{ Lombo } & PPD & 15,39 & 16,51 & 15,25 & 17,15 & 15,75 & 15,81 & 16,21 & 15,21 & 0,2636 & 0,5675 & 0,2477 \\
\hline & $\mathrm{L}^{*}$ & 49,63 & 50,44 & 49,28 & 50,35 & 50,11 & 50,38 & 49,54 & 4,07 & 0,4961 & 0,1559 & 0,1730 \\
\hline & $a^{*}$ & 6,92 & 6,66 & 6,61 & 6,83 & 7,21 & 6,93 & 6,75 & 13,72 & 0,4110 & 0,6999 & 0,2092 \\
\hline & $\mathrm{b}^{*}$ & 3,00 & 3,07 & 3,20 & 3,24 & 3,58 & 3,41 & 3,02 & 28,92 & 0,5925 & 0,2288 & 0,2613 \\
\hline & $\mathrm{C}^{*}$ & 7,64 & 7,38 & 7,37 & 7,59 & 8,09 & 7,78 & 7,44 & 14,36 & 0,3405 & 0,4351 & 0,3965 \\
\hline & $\mathrm{h}^{*}$ & 22,68 & 24,19 & 25,71 & 25,18 & 26,35 & 25,90 & 23,74 & 23,10 & 0,8322 & 0,3153 & 0,0958 \\
\hline & PPC & 24,96 & 24,56 & 26,32 & 27,29 & 27,20 & 26,19 & 25,94 & 14,45 & 0,2820 & 0,9268 & 0,4634 \\
\hline & $\mathrm{pHi}$ & 6,07 & 6,07 & 6,15 & 5,99 & 6,05 & 6,06 & 6,06 & 4,05 & 0,4558 & 0,8292 & 0,9717 \\
\hline & $\mathrm{pHf}$ & 5,35 & 5,32 & 5,37 & 5,31 & 5,32 & 5,34 & 5,32 & 1,14 & 0,1019 & 0,0289 & 0,7616 \\
\hline & $\mathrm{FC}$ & 4,39 & 4,27 & 4,35 & 4,44 & 4,39 & 4,25 & 4,48 & 18,07 & 0,9564 & 0,1874 & 0,8620 \\
\hline \multirow{9}{*}{ Pernil } & PPD & 13,77 & 14,78 & 13,65 & 14,64 & 15,00 & 14,51 & 14,22 & 16,30 & 0,5197 & 0,2751 & 0,3897 \\
\hline & $\mathrm{L}^{*}$ & 44,95 & 45,38 & 45,37 & 46,61 & 44,87 & 45,47 & 45,40 & 4,74 & 0,2590 & 0,5983 & 0,0611 \\
\hline & $a^{*}$ & 8,29 & 8,18 & 8,34 & 7,87 & 8,63 & 8,34 & 8,18 & 12,80 & 0,3742 & 0,8281 & 0,0321 \\
\hline & $\mathrm{b}^{*}$ & 3,15 & 3,14 & 3,33 & 3,42 & 3,64 & 3,37 & 3,29 & 23,09 & 0,4807 & 0,5709 & 0,1016 \\
\hline & $\mathrm{C}^{*}$ & 8,91 & 8,78 & 9,02 & 8,63 & 9,38 & 9,03 & 8,85 & 12,55 & 0,3972 & 0,7287 & 0,0659 \\
\hline & $\mathrm{h}^{*}$ & 20,71 & 21,09 & 21,50 & 23,78 & 22,80 & 22,11 & 21,84 & 19,80 & 0,4350 & 0,5666 & 0,0262 \\
\hline & PPC & 23,11 & 24,15 & 21,34 & 25,91 & 24,19 & 23,71 & 23,77 & 20,07 & 0,1518 & 0,9967 & 0,5764 \\
\hline & $\mathrm{pHf}$ & 5,42 & 5,41 & 5,48 & 5,42 & 5,39 & 5,42 & 5,42 & 1,78 & 0,1358 & 0,3834 & 0,5525 \\
\hline & $\mathrm{FC}$ & 4,59 & 4,30 & 4,18 & 4,57 & 4,45 & 4,57 & 4,26 & 14,85 & 0,4856 & 0,1821 & 0,3282 \\
\hline
\end{tabular}

${ }^{1}$ N, S, N x S: efeito da suplementação com nível de glicerina $(\mathrm{N})$, sexo $(\mathrm{S})$ e sua interação, respectivamente. PPD = Perda de Peso por Descongelamento; $\mathrm{L}^{*}=$ Luminosidade; $\mathrm{a}^{*}=$ Intensidade de vermelho; $\mathrm{b}^{*}=$ Intensidade de amarelo; $\mathrm{C}^{*}=$ Índice de saturação da cor; $\mathrm{h}^{*}=$ Ângulo de tonalidade da cor; $\mathrm{pHi}=\mathrm{ph}$ inicial aos 45 minutos; $\mathrm{pHf}=$ pH final às 24 horas; PPC $=$ Perda de Peso por Cozimento; $\mathrm{FC}=$ Força de Cisalhamento; $\mathrm{CV}=$ Coeficiente de Variação.

$\mathrm{Na}$ literatura, alguns poucos trabalhos que foram desenvolvidos com o objetivo de determinar os efeitos da glicerina, oriunda de diferentes fontes, sobre características de qualidade de carne suína não relataram alterações dos parâmetros avaliados. Mendoza et al. (2010), trabalhando com nível de inclusão de até $150 \mathrm{~g} / \mathrm{kg}$ de glicerina, reportaram um comportamento semelhante ao encontrado neste trabalho, apresentando resultados médios próximos aos deste estudo para o lombo.

Resultados semelhantes aos deste estudo também foram encontrados por Berenchtein et al. (2010) que, trabalhando com glicerina semipurificada $(80 \mathrm{~g} / 100 \mathrm{~g}$ de glicerol) como ingrediente energético das rações de suínos em crescimento e terminação até o nível de $90 \mathrm{~g} / \mathrm{kg}$, não verificaram efeito $(\mathrm{P}<0,05)$ sobre os valores de $\mathrm{pH}$, perda de peso por gotejamento e luminosidade. Lammers et al. (2008), avaliando níveis de 0,50 e $100 \mathrm{~g} / \mathrm{kg}$ de inclusão de glicerina na dieta, também não relataram influência da dieta sobre os parâmetros de qualidade de carne.
A ausência de alterações sobre os parâmetros físico-químicos da carne de suínos com o uso da glicerina pode estar relacionada com as características desse ingrediente, que apresenta valor energético semelhante ao do milho, sendo amplamente absorvido e metabolizado.

Não foi verificada $(\mathrm{P}>0,05)$ influência dos níveis de glicerina, sexo ou interação sobre os valores de $\mathrm{L}^{*}$ (Luminosidade), $\mathrm{b}^{*}$ (Intensidade de amarelo) e $\mathrm{C}^{*}$ (Índice de saturação da cor) dos cortes lombo e pernil (Tab. 3). Esses resultados indicam que, independentemente do nível de utilização da glicerina, esta não promoveu redução, principalmente da intensidade de amarelo, na carne, como preconizado por alguns autores com uso de outros ingredientes em substituição ao milho (Fraga et al., 2008; Watanabe et al., 2010).

Para a intensidade de vermelho ( $\left.\mathrm{a}^{*}\right)$, houve interação do nível de glicerina e sexo, com efeito significativo para os machos castrados (Fig. 1). Contudo, Serrano et al. (2009) não verificaram interação glicerina e sexo sobre os valores de cor. 


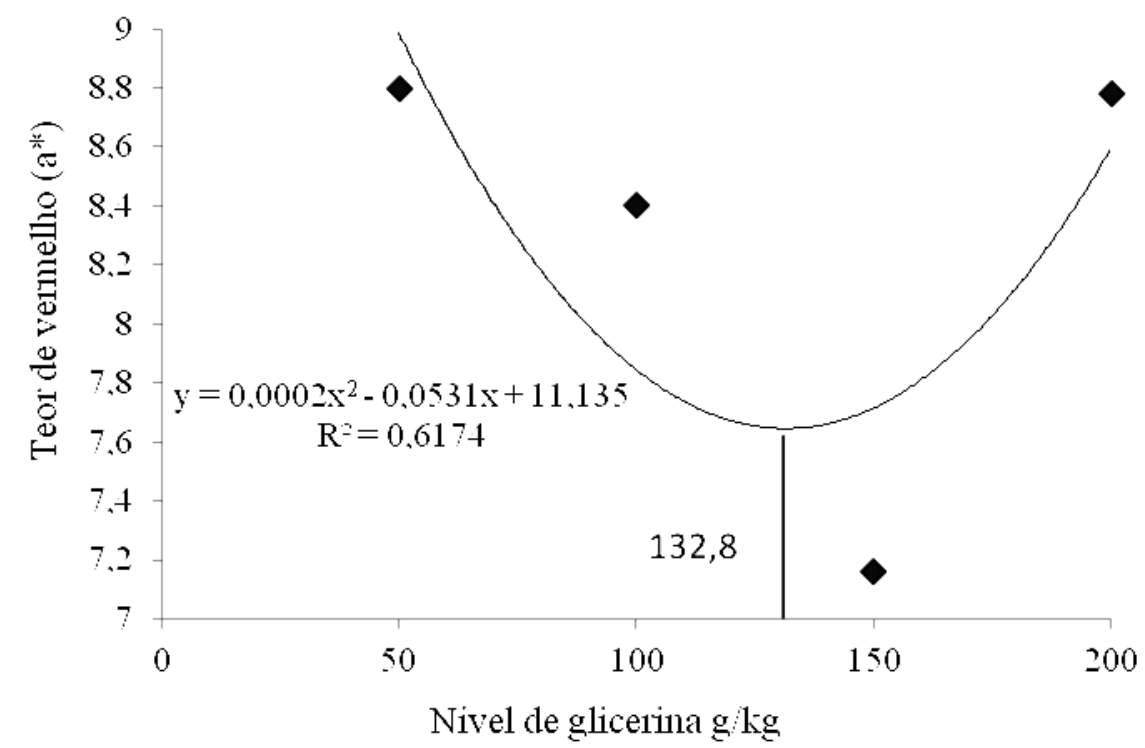

Figura 1. Intensidade de vermelho (a*) do pernil de suínos machos castrados em terminação alimentados com diferentes níveis de glicerina

O nível de glicerina no pernil de machos castrados revelou um comportamento quadrático, apresentando redução da intensidade de vermelho (a*) até o nível de $132,8 \mathrm{~g} / \mathrm{kg}$ de glicerina bruta (Fig. 1).

Esse resultado, por estar relacionado ao aumento da quantidade de glicerol circulante, que, ao ser convertido em glicerol-3-fosfato, seria utilizado pelas mitocôndrias para produção de energia através da fosforilação oxidativa, com consequente produção de agentes oxidantes na célula, como os radicais livres, que promoveriam oxidação de proteínas. Esse efeito pode ter contribuído para a oxidação da própria mitocôndria, uma vez que essa proteína possui grupos prostéticos com a presença de ferro na sua estrutura (Nelson e Cox, 2008).

Não foi observada $(\mathrm{P}>0,05)$ influência dos níveis de glicerina e sexo sobre os valores de perda de peso por descongelamento para o lombo e pernil. Os valores de PPD deste estudo foram superiores aos relatados por Bridi et al. (2006) e Mendoza et al. (2010) e podem ter ocorrido devido aos reduzidos valores de $\mathrm{pH}$ final da carne em ambos os cortes (de 5,33 para o pernil e de 5,42 para o lombo). De acordo com Price e Schweigert (1976), a capacidade de retenção de água no músculo está relacionada com as medidas de $\mathrm{pH}$, sendo que os reduzidos valores desse parâmetro estão associados com maior exsudação de líquido, ocasionado carnes com textura mais seca e menor rendimento após o preparo para consumo.

O valor do índice de saturação da cor $\left(\mathrm{C}^{*}\right)$ apresenta significado em relação à pureza $\mathrm{e}$ intensidade da cor, enquanto o ângulo de tonalidade $\left(\mathrm{h}^{*}\right)$ refere-se à cor propriamente dita (Pomeranz e Meloan, 1971). Neste trabalho, independentemente do nível de glicerina e sexo para o lombo, foi encontrado um valor de $h^{*}$ variando de 22,68 a $26,35^{\circ}$, o que mostra, de acordo com escala de cor no Sistema CieLab, uma tonalidade variando de vermelho ao laranja (Vermelho de 0 a $25^{\circ}$ e Laranja de 25 a $70^{\circ}$ ); porém, com baixa intensidade, com $\mathrm{C}^{*}$ de 7,36 a 8,09 . Para o pernil, os valores observados de $h^{*}$ foram entre 20,70 e $23,78^{\circ}$, mostrando uma cor predominantemente vermelha; contudo, também com baixo índice de saturação (8,62 a 9,37) (Tab. 3).

No pernil, foi encontrada interação entre o nível de glicerina na alimentação e sexo para os valores de $\mathrm{h}^{*}$, revelando um comportamento cúbico para os machos castrados (Fig. 2). 


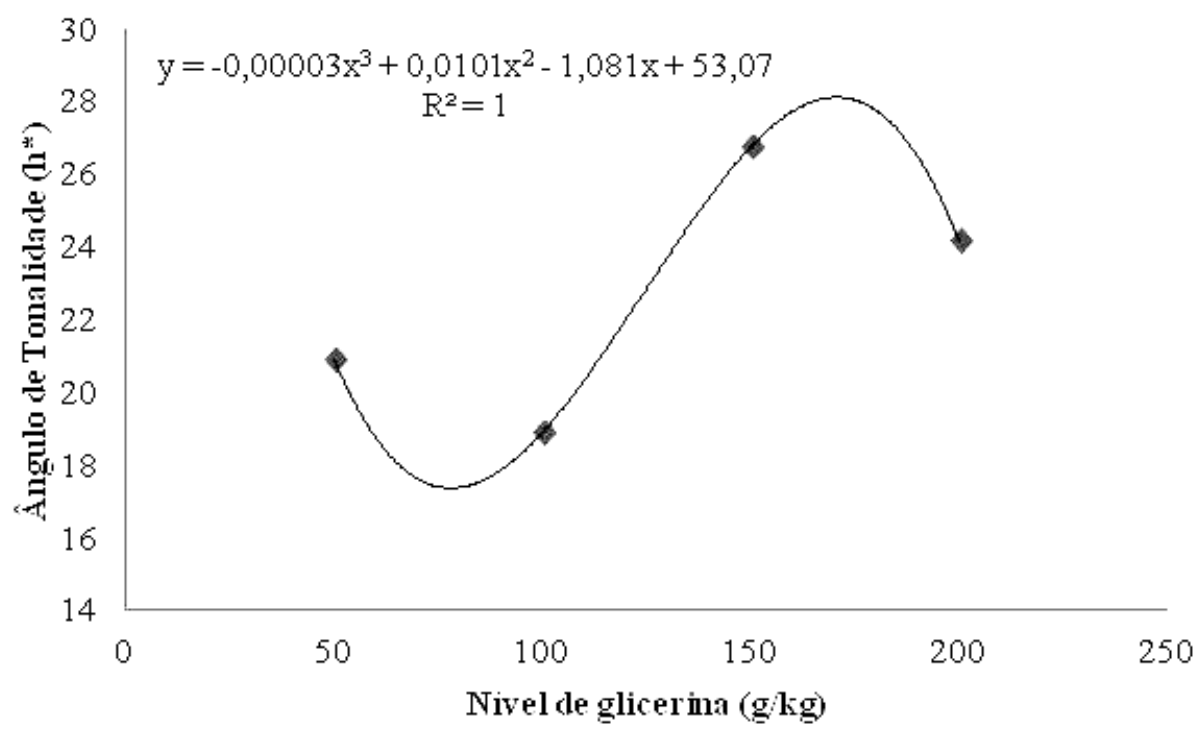

Figura 2. Ângulo de Tonalidade de cor (h*) do pernil de suínos machos castrados, em terminação, alimentados com diferentes níveis de glicerina

O músculo do pernil dos machos castrados com níveis de glicerina de 50 e $100 \mathrm{~g} / \mathrm{kg}$ apresentou uma tonalidade predominantemente vermelha (20,88 e 18,87 , respectivamente), enquanto com níveis de 150 e $200 \mathrm{~g} / \mathrm{kg}$ a carne apresentou uma tendência ao amarelo $(26,73$ e 24,15 , respectivamente). Esse comportamento da tonalidade da cor do pernil dos machos castrados ocorreu em virtude do efeito observado na intensidade de vermelho, uma vez que esse parâmetro é dependente das variações de $a^{*}$ e b* na carne (Brown et al., 2008).

Considerando os critérios adotados por Warner et al. (1997) para classificar as carnes como PSE (Pálida, Mole e Exsudativa), Normal e DFD (Dura, Escura e Seca) de acordo os valores de $\mathrm{pH}$ final, $\mathrm{L}^{*}$ e a perda de água por gotejamento no lombo (carnes são classificadas como Normal quando apresentam valor de $\mathrm{pH}$ final menor que 6,0 , valor de $\mathrm{L}^{*}$ entre 42 e 50 e perda de água menor que $5 \mathrm{~g} / 100 \mathrm{~g}$; PSE, quando o valor de $\mathrm{pH}$ final é menor que 6,0, valor de $\mathrm{L}^{*}$ maior que 50 e perda de água maior que $5 \mathrm{~g} / 100 \mathrm{~g}$; e DFD, quando o valor de $\mathrm{pH}$ final é maior que 6,0 , valor de L* menor que 42 e perda de água por gotejamento menor que $5 \mathrm{~g} / 100 \mathrm{~g}$ ). Os resultados neste trabalho não indicaram carnes com características de ocorrência de anomalias, apesar dos maiores valores de perda de peso por descongelamento e valores de Luminosidade próximos a 50. Essas alterações ocorreram devido à relação do $\mathrm{pH}$ com as miofibrilas e os pigmentos da carne, uma vez que o valor em que ele se estabiliza na carne pode influenciar os parâmetros de cor e a capacidade de retenção de água da carne (Price e Schweigert, 1976; Forrest et al., 1979; Qiao et al., 2001).

$\mathrm{Na}$ avaliação de $\mathrm{pH}$ inicial, não houve diferença $(\mathrm{P}>0,05)$ em relação aos níveis de glicerina e sexo (Tab. 3), e os valores foram superiores a 5,8 , indicando que não houve redução acentuada de $\mathrm{pH}$ com a carcaça ainda quente (temperaturas acima de $30^{\circ} \mathrm{C}$ ), o que poderia, segundo Forrest et al. (1979), promover a desnaturação proteica no músculo, gerando carnes com aspecto de PSE.

Por outro lado, Mourot et al. (1994), utilizando $50 \mathrm{~g} / \mathrm{kg}$ de glicerina oriunda de sebo ou óleo vegetal em dietas para suínos em crescimento e terminação, verificaram que a glicerina acarretou maior capacidade de retenção de água no músculo Longissimus dorsi (lombo), proporcionando uma carne de qualidade superior. $\mathrm{O}$ mesmo foi observado por Gomide et al. (2012), que encontraram menor perda de líquido por descongelamento ao utilizar níveis crescentes de até $160 \mathrm{~g} / \mathrm{kg}$ de glicerina bruta para suínos em terminação. 
Contudo, neste trabalho não houve influência dos diferentes níveis de inclusão de glicerina sobre os parâmetros de perda de peso por descongelamento e cozimento (Tab. 3), demonstrando ausência de efeito osmótico do glicerol e consequente retenção de líquidos nos tecidos musculares.
Nas análises da composição centesimal, verificou-se que não houve $(\mathrm{P}>0,05)$ influência dos níveis de glicerina bruta no lombo para os valores de Umidade, Cinzas, Proteína e Extrato Etéreo; e no pernil, para os valores de Umidade, Proteína e Extrato Etéreo (Tab. 4).

Tabela 4. Composição centesimal dos cortes de lombo e pernil de suínos em função do nível de glicerina na alimentação e do sexo

\begin{tabular}{|c|c|c|c|c|c|c|c|c|c|c|c|c|}
\hline \multirow{2}{*}{ Corte } & \multirow{2}{*}{ Componentes } & \multicolumn{5}{|c|}{$\begin{array}{c}\text { Níveis de glicerina } \\
(\mathrm{g} / \mathrm{kg} \text { de matéria natural })^{1}\end{array}$} & \multicolumn{2}{|c|}{ Sexo } & \multirow{2}{*}{$\begin{array}{l}\mathrm{CV} \\
(\%)\end{array}$} & \multicolumn{3}{|c|}{ Valor de $\mathrm{P}^{2}$} \\
\hline & & 0 & 50 & 100 & 150 & 200 & Macho & Fêmea & & $\mathrm{N}$ & S & $\mathrm{N} \times \mathrm{S}$ \\
\hline \multirow{4}{*}{ Lombo } & Umidade & 73,45 & 73,99 & 74,30 & 74,01 & 74,15 & 73,65 & 74,31 & 1,72 & 0,9281 & 0,0608 & 0,9738 \\
\hline & Cinzas & 1,25 & 1,12 & 1,10 & 1,23 & 1,23 & 1,17 & 1,20 & 13,56 & 0,1188 & 0,7455 & 0,7549 \\
\hline & Proteína & 22,94 & 21,61 & 20,70 & 21,07 & 21,78 & 21,70 & 21,54 & 8,24 & 0,4268 & 0,6820 & 0,2711 \\
\hline & E. Etéreo & 2,33 & 2,23 & 2,54 & 2,29 & 2,38 & 2,87 & 1,83 & 44,88 & 0,8736 & 0,0001 & 0,3011 \\
\hline \multirow{4}{*}{ Pernil } & Umidade & 74,10 & 74,39 & 74,10 & 73,71 & 72,93 & 73,61 & 74,08 & 2,19 & 0,2084 & 0,2251 & 0,3021 \\
\hline & Cinzas & 1,20 & 1,08 & 1,21 & 1,17 & 1,18 & 1,12 & 1,28 & 12,49 & 0,1287 & 0,1336 & 0,0459 \\
\hline & Proteína & 22,36 & 22,13 & 22,10 & 22,79 & 22,41 & 21,88 & 22,84 & 7,83 & 0,7217 & 0,0306 & 0,1212 \\
\hline & E. Etéreo & 2,00 & 2,25 & 2,67 & 2,68 & 2,78 & 3,04 & 1,91 & 39,83 & 0,5984 & 0,0001 & 0,2069 \\
\hline
\end{tabular}

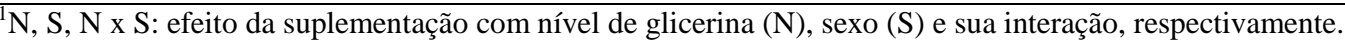

De acordo com Lin (1977) e Tao et al. (1983), o glicerol é um precursor para a síntese de glicose, de triacilglicerois e de fosfolípidos no fígado e no tecido adiposo, atuando como agente da gliconeogênese, contribuindo para redução da catálise proteica e/ou atividade de lipogênese. Entretanto, não foi observado esse efeito sobre os parâmetros estudados e esse resultado pode estar relacionado à formulação das dietas, uma vez que estas foram isoenergéticas e isoproteicas, demonstrando o potencial de uso da glicerina em substituição ao milho. Resultados semelhantes foram relatados por Lammers et al. (2008), que também não encontraram influência do uso de glicerina sobre os valores de umidade e lipídeos totais no músculo Longissimus dorsi.

Entretanto, no lombo e pernil, os machos castrados apresentaram maior valor de extrato etéreo $(\mathrm{P}<0,05)$ quando comparados às fêmeas. Os resultados deste trabalho corroboram os de Fialho et al. (1998), Latorre et al. (2003) e Rosa et al. (2008). Segundo esses autores, isso está relacionado ao fato de as fêmeas suínas serem mais eficientes que os machos castrados na produção de carne, uma vez que estes apresentam, de forma geral, maior deposição e quantidade de gordura na musculatura que as fêmeas. Da mesma forma, também foram verificados maiores valores de proteína no pernil para as fêmeas (Tab. 4), demonstrando o efeito anabólico sobre a deposição muscular nessa categoria sexual.

A análise estatística revelou interação entre os diferentes níveis de glicerina e sexo para o teor de cinzas no pernil dos suínos, mostrando comportamento diferenciado em relação ao sexo, com efeito quadrático para machos castrados, que mostraram um maior teor de cinzas no nível de $156,67 \mathrm{~g} / \mathrm{kg}$ de glicerina na alimentação (Fig. 3).

Os machos castrados apresentaram menores valores de cinzas em relação às fêmeas na carne do pernil (Tab. 4). Esse comportamento para os valores de cinzas encontrados para os machos castrados pode ser reflexo da menor deposição de proteína, uma vez que o conteúdo mineral do músculo está associado a compostos orgânicos que participam dos processos de contração muscular (Prändl et al., 1994; Lawrie, 2005).

De forma geral, o uso de até $200 \mathrm{~g} / \mathrm{kg}$ de glicerina na alimentação não promoveu alterações que prejudicassem os aspectos físico-químicos e da composição centesimal da carne de suínos, mostrando ser um ingrediente com grande potencial de uso na suinocultura, melhorando os aspectos de produção através de redução de custos e aproveitamento sustentável desse resíduo da indústria do biodiesel. 


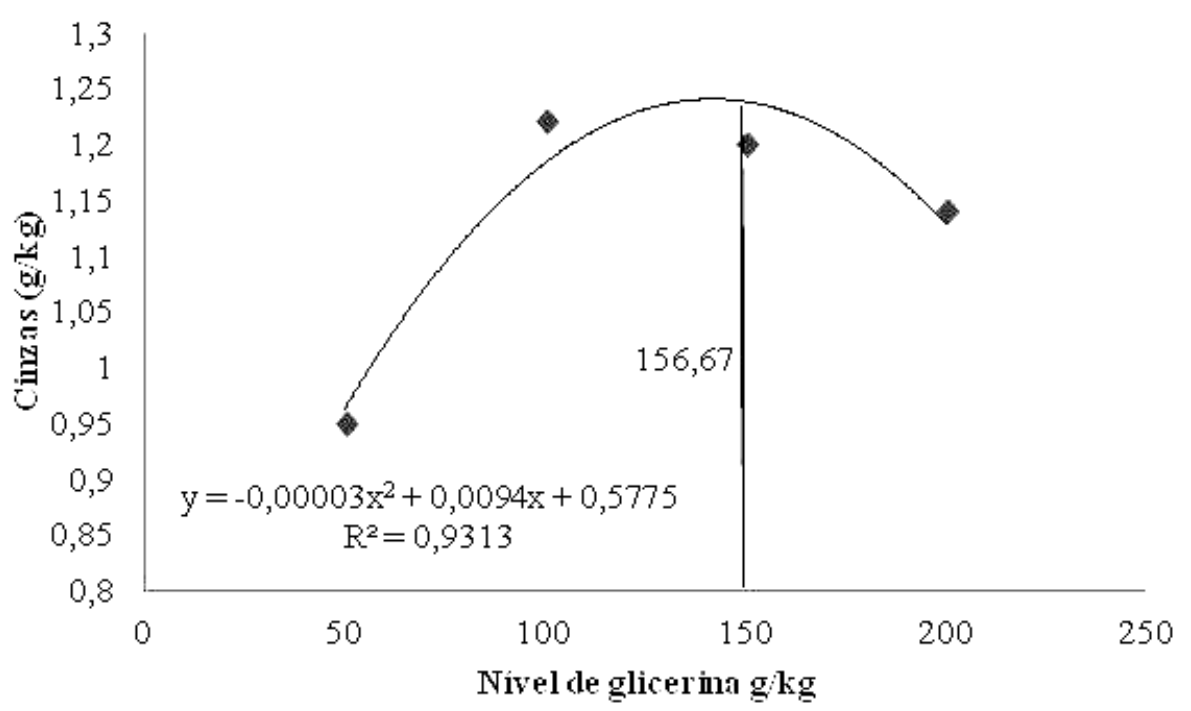

Figura 3. Teor de cinzas do pernil de suínos machos castrados, em terminação, alimentados com diferentes níveis de glicerina.

\section{CONCLUSÃO}

$\mathrm{Na}$ alimentação de suínos, a glicerina bruta mostra ser um ingrediente que não ocasiona modificações dos aspectos físico-químicos e bromatológicos da carne de lombo e pernil, não influenciando as características de qualidade e valor nutricional, independentemente do nível de inclusão utilizado.

\section{AGRADECIMENTO}

Á FAPEMIG (Fundação de Amparo à Pesquisa do Estado de Minas Gerais), que promove atividades de fomento, apoio $\mathrm{e}$ incentivo a pesquisas científicas e tecnológicas em Minas Gerais, possibilitando a realização do estudo por meio do fornecimento de auxílio financeiro.

\section{REFERÊNCIAS}

AGÊNCIA nacional de petróleo. Anuário estatístico brasileiro do petróleo, gás natural e biocombustíveis. Disponível em: <http://www.anp.gov. br/>. Acessado em: 28 set. 2012.

AMASA. Guidelines for cooking sensory evaluation of meat. American Meat Science Association, National Live Stock and Meat Board: Chicago, 1978. 24p.
BERENCHTEIN, B.; COSTA, L.B.; BRAZ, D.B. et al. Utilização de glicerol na dieta de suínos em crescimento e terminação. Rev. Bras. Zootec., v.39, p.1491-1496, 2010.

BRIDI, A.M.; OLIVEIRA, A.R.; FONSECA, N.A.N. et al. Efeito do genótipo halotano, da ractopamina e do sexo do animal na qualidade da carne suína Rev. Bras. Zootec., v.35, p.20272033, 2006.

BROWN, S.N.; NUTE, G.R.; BAKER, A. et al. Aspects of meat and eating quality of broiler chickens reared under standard, maize-fed, freerange or organic systems. Br. Poult. Sci., v.49, p.118-124, 2008.

FAROUK, M.M.; PRICE, J.F. The effect of post-exsanguination infusion on the composition, exudation, color and post-mortem metabolic changes in lamb. Meat Sci., v.38, p.477-496, 1994.

FIALHO, E.T.; OLIVEIRA, A.I.G.; LIMA, J.A.F. et al. Influência de planos de nutrição sobre as características de carcaça de suínos de diferentes genótipos abatidos entre 80 e $120 \mathrm{~kg}$. Rev. Bras. Zootec., v.27, p.1140-1146, 1998.

FORREST, J.C.; ABERLE, E.D.; HEDRICK, H.B. et al. Fundamentos de ciencia de la carne. Zaragoza: Acribia, 1979. 364p.

FRAGA, A.L.; THOMAZ, M.C.; KRONKA, R.N. et al. Restrição alimentar qualitativa para 
suínos com elevado peso de abate. Rev. Bras. Zootec., v.37, p.869-875, 2008.

FRONING, G.W.; UIJTTENBOOGAART, T.G. Effect of post mortem electrical stimulation on color, texture, $\mathrm{pH}$ and cooking loses of hot and cold deboned chicken broiler breastmeat. Poult. Sci., v.67, p.1536-1544, 1988.

GOMIDE, A.P.C.; BRUSTOLINI, P.C.; FERREIRA, A.S. et al. Substituição do milho por glicerina bruta em dietas para suínos em terminação. Arq. Bras. Med. Vet. Zootec., v.64, p.1309-1316, 2012.

HORWITZ, W. Official methods of analysis of Association of Official Analytical Chemists. 13.ed. Whashington: AOAC, 1990. 1018p.

LAMMERS, P.J.; KERR, B.J; WEBER, T.E. et al. Growth performance, carcass characteristics, meat quality, and tissue histology of growing pigs fed crude glycerin-supplemented diets. $J$. Anim. Sci., v.86, p.2962-2970, 2008.

LATORRE, M.A.; LAZARO, R.; GRACIA, M.I. et al. Effect of sex and terminal sire genotype on performance, carcass characteristics, and meat quality of pigs slaughtered at $117 \mathrm{~kg}$ body weight. Meat Sci., v.65, p.1369-1377, 2003.

LAWRIE, R. A. Ciência da carne. Tradução de Jane Maria Rubensan. Porto Alegre, Ed. Artmed, $6^{\circ}, 2005.384 \mathrm{p}$.

LIN, E.C.C. Glycerol utilization and its regulation in mammals. Annu. Rev. Biochem., v.46, p.765-795, 1977.

MENDOZA, O.F.; ELLIS, M.; MCKEITH, F.K. et al. Metabolizable energy content of refined of glycerin and its effects on growth performance and carcass and pork quality characteristics of finishing pigs. J. Anim. Sci., v.88, p.3887-3895, 2010 .

MOUROT, J.; AUMAITRE, A.; MOUNIER, A. et al. Nutritional and physiological effects of dietary glycerol in the growing pig. Consequences on fatty tissues and post mortem muscular parameters. Livest. Prod. Sci., v.38, p.237-244, 1994.

NELSON, D.L.; COX, M.M. Lehninger Principles of Biochemistry. 5th ed. W.H. Freeman: New York, 2008. 1100p.
POMERANZ, Y.; MELOAN, C.E. Food Analysis: Theory and practice. 1. ed. Westpot Connecticut: The AVI Publishing Company Corporation, 1971. 669p.

PRÄNDL, O.; FISCHER, A.; SCHMIDHOFER, T. et al. Tecnología e hygiene de la carne. Zaragoza: Acribia, 1994. 854p.

PRICE, J.F.; SCHWEIGGERT, B.S. Ciência de la carne y de los productos carnicos. Zaragoza: Acribia, 1976. 668p.

QIAO, M.; FLETCHER, D.L.; SMITH, D.P. et al. The effect of broiler breast meat color on $\mathrm{pH}$, moisture, water-holding capacity, and emulsification capacity. Poult. Sci., v.80, p.676680, 2001.

RAMOS, E.M.; GOMIDE, L.A.M. Avaliação da Qualidade de Carnes: fundamentos e metodologias. Viçosa: UFV, 2007. 599p.

ROSA, A.F.; GOMES, J.D.F.; MARTELLI, M.R. et al. Características de carcaça de suínos de três linhagens genéticas em diferentes idades ao abate. Cienc. Rural, v.38, p.1718-1724, 2008.

ROSTAGNO, H.S.; ALBINO, L.F.T.; DONZELE, J.L. et al. Tabelas brasileiras para aves e suínos, composição de alimentos e exigências nutricionais. 2. ed. Viçosa: UFV, 2005. 186p.

SERRANO, M.P.; VALENCIA, D.G.; FUENTETAJA, A. et al. Influence of feed restriction and sex on growth performance and carcass and meat quality of Iberian pigs reared indoors. J. Anim. Sci., v.87, p.1676-1685, 2009.

TAO, R.C.; KELLEY, R.E.; YOSHIMURA, N.N. et al. Glycerol: Its metabolism and use as an intravenous energy source. JPen-Parenter Enter, v.7, p.479-488, 1983.

WARNER, R.D.; KAUFFMAN, R.G.; RUSSEL, R.L. Muscle protein changes post mortem in relation to pork quality traits. Meat Sci., v.45, p.339-352, 1997.

WATANABE, P.H.; RUIZ, U.S.; SANTOS, V.M. et al. Carcass characteristics and meat quality of heavy swine fed different citrus pulp levels. Arq. Bras. Med. Vet. Zootec., v.62, p.921929, 2010. 